\title{
An Experimental Evaluation of Etching Depth for Different steels by using Photochemical Machining
}

\author{
Akash A. Pawar, Nitin D. Misal, Avinash D. Sapkal, Rohit H. More, Bandu A. Kamble
}

\begin{abstract}
Photochemical machining (PCM) used to machine metal parts employing a photoresist and etchants. It is critical non-conventional machining process.Non-conventional machining forms are broadly used within the fabricate of geometrically challenging machining components from designing fabric which are not imagable machining process. The focus of this work is parametric optimization for steel photochemical machining (PCM). Etching temperature and etching time were used as control parameters..PCM was performed with ferreous chloride as the etchant.Surface roughness and edge nonconformity were reduced, however etching depth was desired at a greater extent.The objective of the investigation is to see how control factors affect reaction parameters., viz surface roughness, etching depth, and parameter optimization with different weight rates for each performance measured.Tofulfilling this OEC is utilized by allotting diverse weight rate to reaction parameters.

Index Terms - Photo Chemical Machining, Photo tool, etching, Changing etching parameters, overall evaluation criteria (OEC).
\end{abstract}

\section{INTRODUCTION}

The photo chemical machining process is also named as, photo chemical etching,chemical milling, chemical etching, photo etching and even the abbreviation "PCM." The PCM industry currently plays aenergetic role in the construction of a variety of precision parts viz. micro fluidic channels, silicon combined circuits, copper printed circuit boards and attractive items having thickness less than 2mm.PCM is one of the most widely used non-traditional machining techniques combining photographic and chemical etching techniques. The procedure begins with the part's shape being created on optically clear and excellent dimensional photographic film.. The procedure begins with the creation of a needed design in AutoCAD software called a photo tool, which is then printed on a transparent sheet of plastic for etching.An experimental investigation was carried out to recognize ideal values of parameters using ferric chloride $(\mathrm{FeCl} 3)$ as an etchant. In his work talked about on assessing the ideal machining parameters required for photochemical machining of an Inconel 718 and impacts of these parameters on surface topology. The parameters considered in this examination are concentration of etchant, etching time, and etchant temperature.

Akash A. Pawar, M. Tech student, SVERI's College of Engineering, Pandharpur

Nitin D. Misal, Proffesor, SVERI's College of Engineering, Pandharpur Avinash D. Sapkal, Lecture, SVERI's College of Engineering, Pandharpur Rohit H. More, Lecture, SVERI's College of Engineering, Pandharpur Bandu A. Kamble, Research Scholar, SVERI's College of Engineering, Pandharpur
The experimental examination appears that etching executio $\mathrm{n}$ aswellassurface topology progressed.

PCM depth can be achieved by exposing fewer and fewer tests at a time.The less and more intensified light will be passing in photo tool. The photo tool is prepared by making diverse on a straightforward piecepaper.The light that comes out of various sources is determined by the photo tool's

characteristics. The vitality of substance is changing with colour,This results in the photoresist fabric being less and less solidified.The enhancement of photoresist fabric is crucial for the etching handle.Less creating comes about in less carving and more creating comes about in more carving[1-3]. The idea about positive and negative type photoresist composition and its reactions with UV light is explained. Also given the comparison between positive photoresist and negative photoresist.The effect of liquid type photoresist for photochemical machining,in this article different photoresist types was described and focused on liquid photo imageable etch resists to produce functional or decorative metal parts. For parametric optimization of PCM for brass and german silver, a two-dimensional simulation model of etching was established, and the experimental study of process parameters on micro-geometry was studied.[4-6]

PCM has broadly utilized within the fabricating of lean, level and pieces made of metal that are complicated (i.e. lead outlines, colour TV veils, instruments, warm plates, reproduced circuit sheets) in gadgets, exactness engineering

and enriching businesses within the past forty a long time. Presently adaysPCMindustryplays vital part in generati on of assortments of exactness parts, enriching components and to create Copper printed circuit sheets, microfluidic channels, and microfilters etc. The use of a grey-based Taguchi technique for optimising PCM process parameters in etching while taking numerous output parameters into account is described. The grey relational analysis is used to solve the PCM process in this innovative technique.The performance characteristic is a grey relation grade produced from the grey relational analysis. Depth of etching in PCM can be varied by changing temperature and time of etching.OEC analysis can be used for achieving optimum condition for etching depth and surface roughness.[7-10]. Different researchers [11-25] have reported the micro features, micro channel heat sink, textured bearing, etc. fabrication using photochemical machining on various materials and also by employing laser engraving method. The parametric analysis was also reported.

The photoresist used PCM has two types given below. 


\section{An Experimental Evaluation of Etching Depth for Different steels by using Photochemical Machining}

\section{Positivephotoresist}

Negativephotoresist

In negative photoresist, the grey piece of the photo-tool is eliminated, and the remaining portion of the photo-tool becomes hard,and in positive photoresist contrarily like negative photoresist is dull is stay difficult and the portion which up milder which non solidify portion is evacuated.

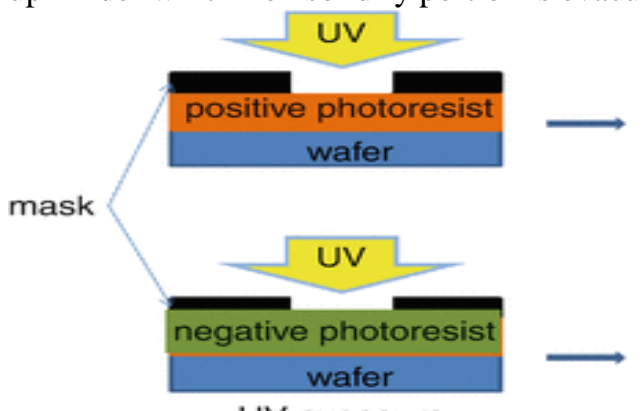

UV exposure

Fig.1 Types of photoresist

\section{METHODOLOGY}

\section{A. Material selection}

Steel is the material that was considered in this study, since it is harder than copper and aluminium, thus it is necessary to research steel machining characteristics. The specimen size used was $25 \mathrm{~mm}$ x $25 \mathrm{~mm}$ x $5 \mathrm{~mm}$ (WLT). Steel flat surfaces were subjected to PCM. For experiments, Fecl3 is implemented as an etchant and a negative photoresist.

\section{B. Experimental procedure}

\section{1) CreatingPhoto tool}

The photochemical machining technique is approved once a photo is taken. Thephoto tool consists of an AutoCAD drawing with full-size versions of the desired shape printed transparent paper.

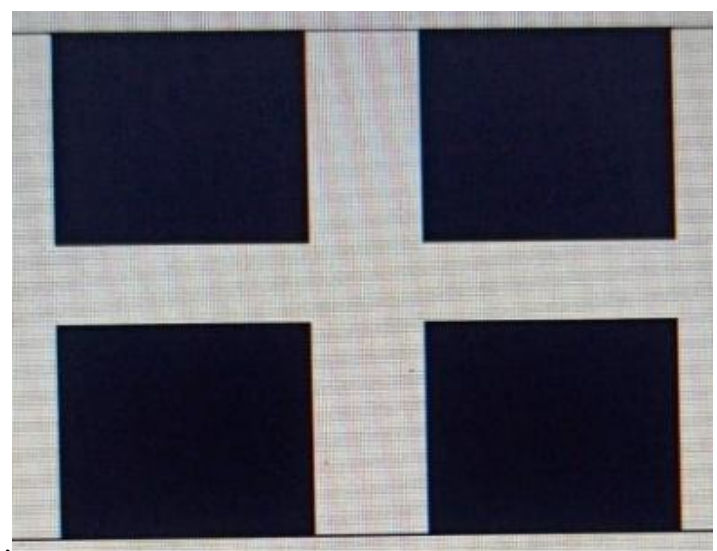

Fig.2 Photo toolinAutoCAD

\section{Preparation of workpiece.}

Afterwards planning the photo tool the steel fabric is cut into essential measure. The cleaning of thesteel plates are main task,i.e first by sand paper later bythinner(trichloroethylene or acetone). This process is carried out to ensure that the workpiece's surface is free of foreign particles, dirt, oils, and other pollutants. So to have a great hold of photoresist with the metal surface.

\section{Coating of workpiece.}

A light coating of photoresist is deposited to the metal surface after the object has been cleaned.For testing purposes, a negative type photo resister was used.The property of negative photoresist is that it solidifies when exposed to UV light.The properties of negative photoresist is different for different colors.

\section{UV Exposure.}

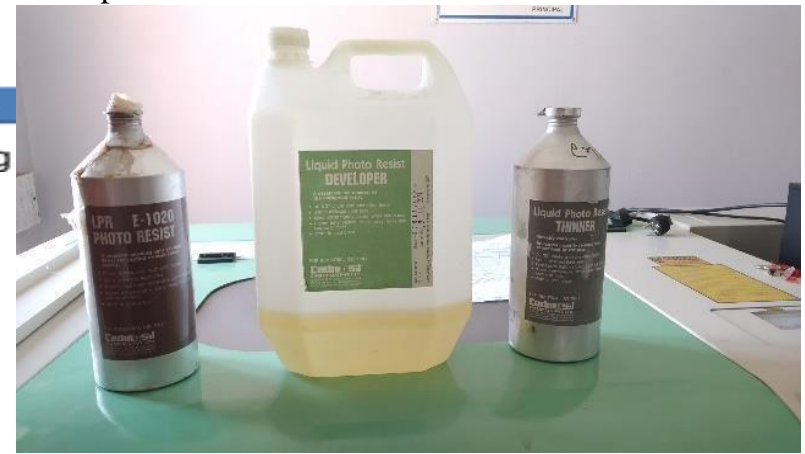

\section{UV Exposure.}

Fig.3 Photoresist and Developing Solution

In PCM, its essential to exposes all bearings' fabric (base metal), all bearings can have etching applied on them. The 1 KW control UV light bulb is utilized for uncovering the test. It transmits the escalated 1800 microwatt per centimeter squareat $25 \mathrm{~cm}$ remove.In conventional machiningi.e.in2D

PCM prepare the tests are uncovered in as it were one heading. The coated workpiece receives the photo equipment that has been created and uncovered to for 90 seconds, used a UV source.

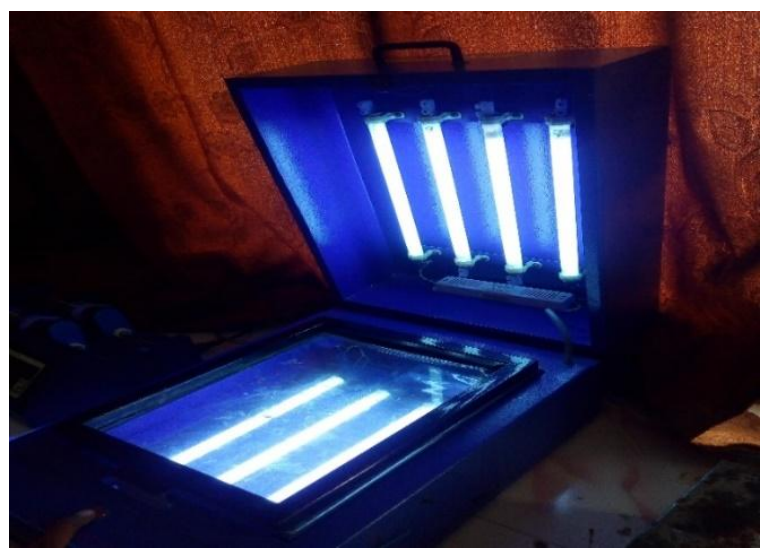

Fig.4 Exposure machine

\section{Development Phase.}

A solution of sodium carbonate and water is often used to produce the arrangement. After this steel plate isdiped in the developer for 90 seconds, as a result imprerssion occurred on plate. Afterwards steel plate is washed with water.Etching process relates on photoresist enhancement. 


\section{Etching}

Afterwards the steel plate is kept in etching solution. The etching solution is the mixture of $\mathrm{FeCl}_{3}$ and water. Due to late etching process etching of steel plate is take place. In black colour photo tool ordinary etching happen and there is no etching is there on white colour.The photoresist thickness is changing with color.

\section{EXPERIMENTAL ANALYSIS}

Several experiments are conducted to investigate the etching behaviour of Steel fabric using i parameters such as etching time, temperature, surface roughness, as well as reaction parameters such as etching depth and surface roughness.Throughout the studies, thephotoresistbreadth, exposure time, and developing time are all kept constant.Table 1 shows the experimentation plan matrix as well as the steel response parameters that were recorded. With the help of Mitutoyo surface roughness analyzer Ra was measured and depth bythe digital micrometer.For fulfilling this OEC was used.The surface roughness of each piece of steel was

Table 1. Experimental design matrix for $\mathrm{EN} 1 \mathrm{~A}$ Steel $(\mathrm{C}=0.07 \%)$ with response measures and OEC values

\begin{tabular}{|c|c|c|c|c|c|c|c|c|c|}
\hline $\begin{array}{l}\text { Expt } \\
\text { No. }\end{array}$ & $\begin{array}{l}\text { Tem } \\
\text { p. }\left({ }^{\circ} \mathrm{C}\right)\end{array}$ & $\begin{array}{r}\text { Tim } \\
\text { e (min) }\end{array}$ & $\begin{array}{c}\text { Etching } \\
\text { Depth }(\mathrm{mm})\end{array}$ & $\begin{array}{r}\mathrm{Ra} \\
(\mu \mathrm{m})\end{array}$ & ${ }_{1} \mathrm{OEC}$ & $2^{\mathrm{OEC}}$ & 3 OEC & ${ }_{4}$ OEC & 5 OEC \\
\hline 1 & 40 & 30 & 0.031 & 0.062 & 15 & 35 & 50 & 65 & 85 \\
\hline 2 & 40 & 60 & 0.045 & 2.265 & $3^{20.3}$ & $8^{19.5}$ & $\begin{array}{ll} & 19.0 \\
2 & \end{array}$ & $6^{18.4}$ & $\begin{array}{ll} & 88.1 \\
3 & \end{array}$ \\
\hline 3 & 40 & 90 & 0.073 & 2.721 & $8^{53.2}$ & $4^{40.7}$ & $4^{31.3}$ & $\begin{array}{r}21.9 \\
4^{2}\end{array}$ & 9.4 \\
\hline 4 & 40 & 120 & 0.098 & 0.801 & $3^{95.8}$ & $7^{90.2}$ & 86.1 & $3^{81.9}$ & $\begin{array}{l}76.3 \\
7\end{array}$ \\
\hline 5 & 50 & 30 & 0.035 & 2.041 & 9.44 & $2^{22.0}$ & $7^{31.4}$ & $2^{40.9}$ & $1^{53.5}$ \\
\hline 6 & 50 & 60 & 0.053 & 5.185 & $5^{21.8}$ & $\begin{array}{ll} & 16.7 \\
1 & \end{array}$ & $\begin{array}{ll} & 12.8 \\
5 & \end{array}$ & 9.01 & 3.85 \\
\hline 7 & 50 & 90 & 0.085 & 0.191 & $\begin{array}{l}75.7 \\
1\end{array}$ & $\begin{array}{ll} & 81.4 \\
2 & \end{array}$ & $\begin{array}{l}85.7 \\
1\end{array}$ & $\begin{array}{l}90.0 \\
8\end{array}$ & $\begin{array}{r}95.7 \\
1\end{array}$ \\
\hline 8 & 50 & 120 & 0.105 & 4.177 & $2^{88.0}$ & $6^{72.0}$ & $9^{60.0}$ & $\begin{array}{ll} & 48.1 \\
1 & \end{array}$ & $5^{32.1}$ \\
\hline 9 & 60 & 30 & 0.042 & 7.157 & 5.25 & $6^{12.2}$ & $2^{17.5}$ & $7^{22.7}$ & $8^{29.7}$ \\
\hline 10 & 60 & 60 & 0.051 & 9.463 & 8.79 & 6.72 & 5.17 & 3.62 & 1.55 \\
\hline 11 & 60 & 90 & 0.093 & 3.341 & $8^{63.7}$ & $6^{70.6}$ & $\begin{array}{ll} & 75.8 \\
3 & \end{array}$ & $9^{80.9}$ & $\begin{array}{l}87.8 \\
7\end{array}$ \\
\hline 12 & 60 & 120 & 0.129 & 2.277 & $\begin{array}{l}96.8 \\
7\end{array}$ & $0^{92.3}$ & $\begin{array}{ll} & 88.1 \\
3 & \end{array}$ & $\begin{array}{l}91.8 \\
7\end{array}$ & $1^{97.6}$ \\
\hline
\end{tabular}

measured in three places, and the average value was used to complete the study. 
Table 2. EN 8 Steel $(C=0.35 \%)$ experimental design matrix with response measurements and OEC values

\begin{tabular}{|c|c|c|c|c|c|c|c|c|c|}
\hline $\begin{array}{l}\text { Expt. } \\
\text { No. }\end{array}$ & $\begin{array}{l}\text { Temp } \\
.\left({ }^{\circ} \mathrm{C}\right)\end{array}$ & $\begin{array}{l}\text { Time } \\
\text { (min) }\end{array}$ & $\begin{array}{c}\text { Etching } \\
\text { Depth }(\mathrm{mm})\end{array}$ & $\operatorname{Ra}(\mu \mathrm{m})$ & ${ }_{1}^{\text {OEC }}$ & $2^{\mathrm{OEC}}$ & $3^{\text {OEC }}$ & $4^{\text {OEC }}$ & $5^{\text {OEC }}$ \\
\hline 1 & 40 & 30 & 0.017 & 1.880 & 10.12 & 30.22 & 25.14 & 40.25 & 34.56 \\
\hline 2 & 40 & 60 & 0.038 & 1.528 & 27.82 & 30.34 & 32.24 & 34.13 & 36.65 \\
\hline 3 & 40 & 90 & 0.068 & 0.967 & 68.51 & 75.92 & 81.48 & 87.03 & 94.44 \\
\hline 4 & 40 & 120 & 0.098 & 1.418 & 92.59 & 82.71 & 75.30 & 67.89 & 58.01 \\
\hline 5 & 50 & 30 & 0.004 & 2.943 & 14.66 & 32.15 & 30.22 & 18.96 & 45.60 \\
\hline 6 & 50 & 60 & 0.007 & 1.397 & 15.51 & 29.84 & 40.59 & 51.34 & 65.67 \\
\hline 7 & 50 & 90 & 0.018 & 0.920 & 33.88 & 49.44 & 61.11 & 72.77 & 88.33 \\
\hline 8 & 50 & 120 & 0.067 & 0.939 & 99.85 & 99.67 & 99.53 & 99.38 & 99.20 \\
\hline 9 & 60 & 30 & 0.040 & 1.176 & 14.45 & 33.72 & 48.17 & 62.62 & 81.89 \\
\hline 10 & 60 & 60 & 0.045 & 0.998 & 23.32 & 41.09 & 54.42 & 67.75 & 85.52 \\
\hline 11 & 60 & 90 & 0.060 & 8.002 & 34.55 & 26.69 & 20.47 & 14.22 & 6.89 \\
\hline 12 & 60 & 120 & 0.090 & 0.917 & 99.80 & 98.05 & 98.55 & 97.88 & 98.10 \\
\hline
\end{tabular}

\section{RESUlT ANDDISCUSSION}

For Study of PCM surface roughness and etching depth of Steel was considerd. The test data examined in respect of effect of temperature and time on $\mathrm{Ra}$ and etching depth. From Tables 1 and 2, the bold value reflects the optimum output of all OECs, signifying the optimum performance measure condition. Figures 5, 6, and 7 illustrate the normal effect of temperature and etching time on etching depth for steel, while figures 8,9 , and 10 demonstrate the effect on surface roughness. The lowest etching depth value was found at $40^{\circ} \mathrm{C}$ temperature and 30 minutes, while the highest value was found at $60^{\circ} \mathrm{C}$ temperature and 120 minutes.According to $\mathrm{OEC}$ research, the ideal conditions for $\mathrm{EN} 1 \mathrm{~A}$ steel are $60^{\circ} \mathrm{C}$ temperature and 120 minutes, while the ideal conditions for $\mathrm{EN} 8$ steel are $50^{\circ} \mathrm{C}$ temperature and 120 minutes. 
A. Effect of Temperature and Etching Time on Etching Depth

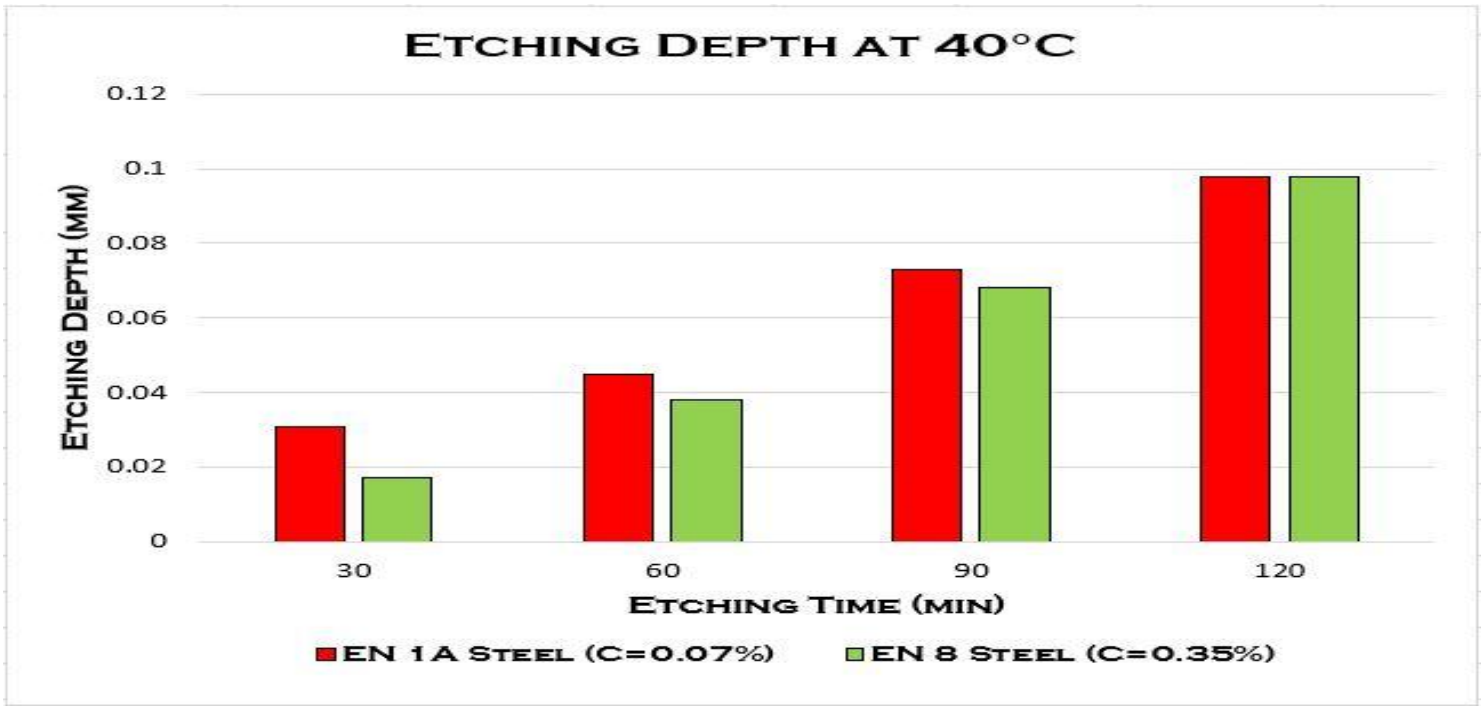

Fig.5 Etching depth at $40^{\circ} \mathrm{C}$

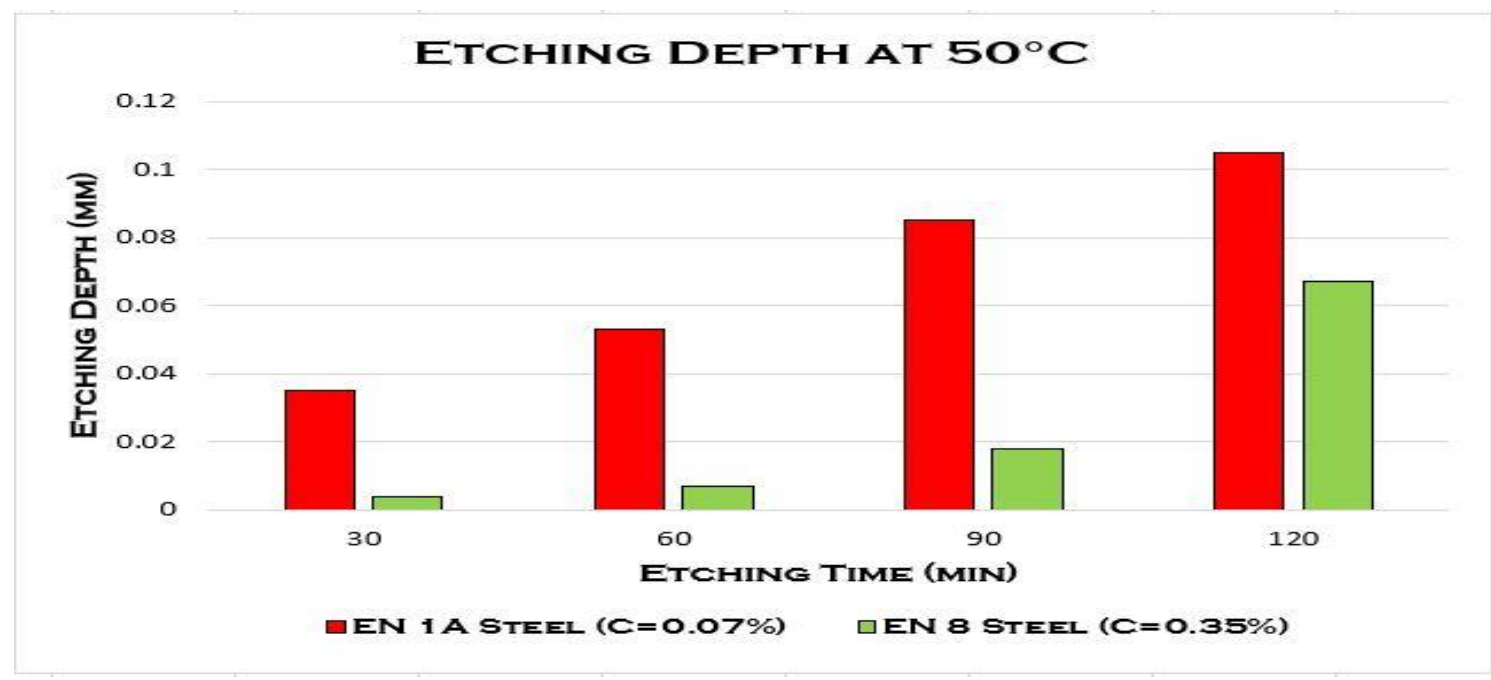

Fig.6 Etching depth at $50^{\circ} \mathrm{C}$

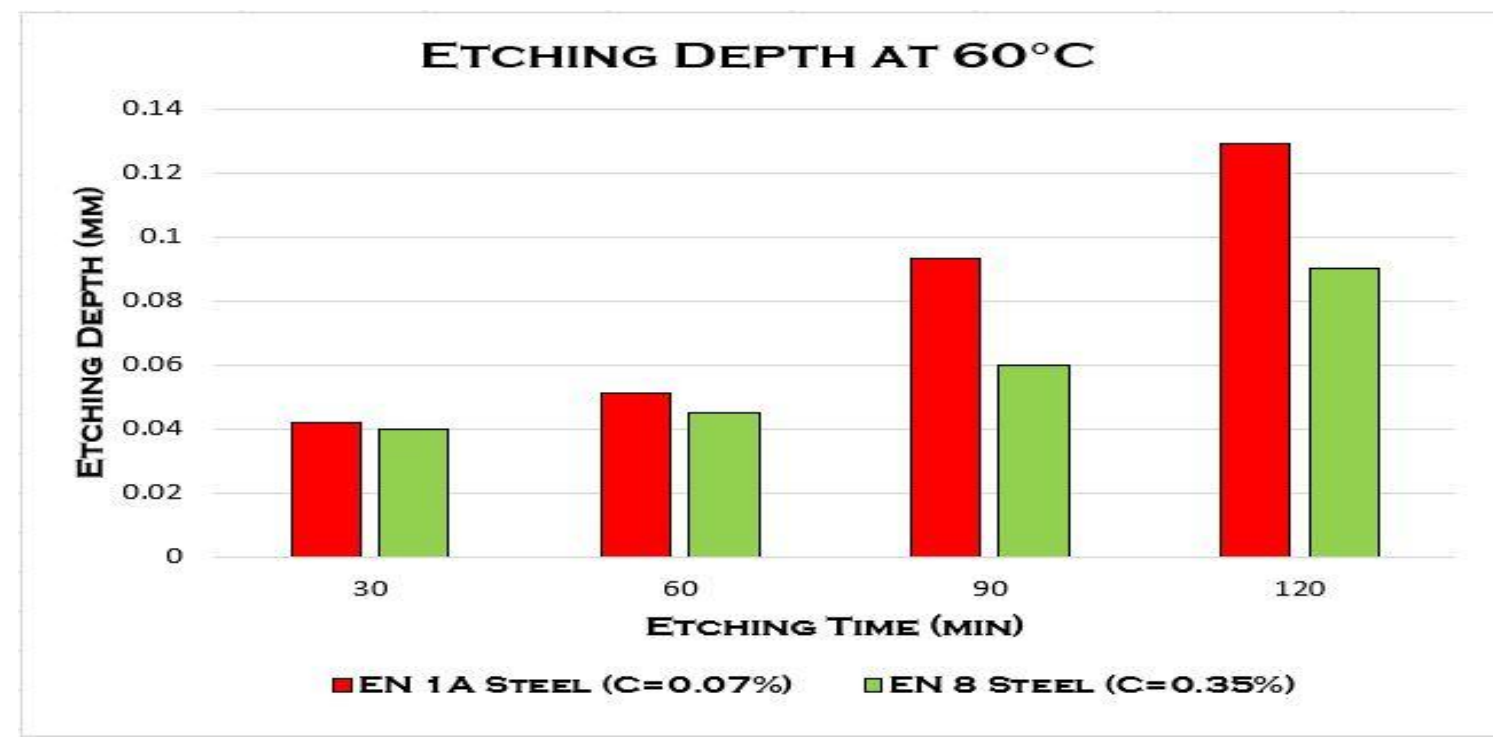

Fig.7 Etching depth at $60{ }^{\circ} \mathrm{C}$ 
B. Effect of Temperature and Etching Time on Surface Roughness

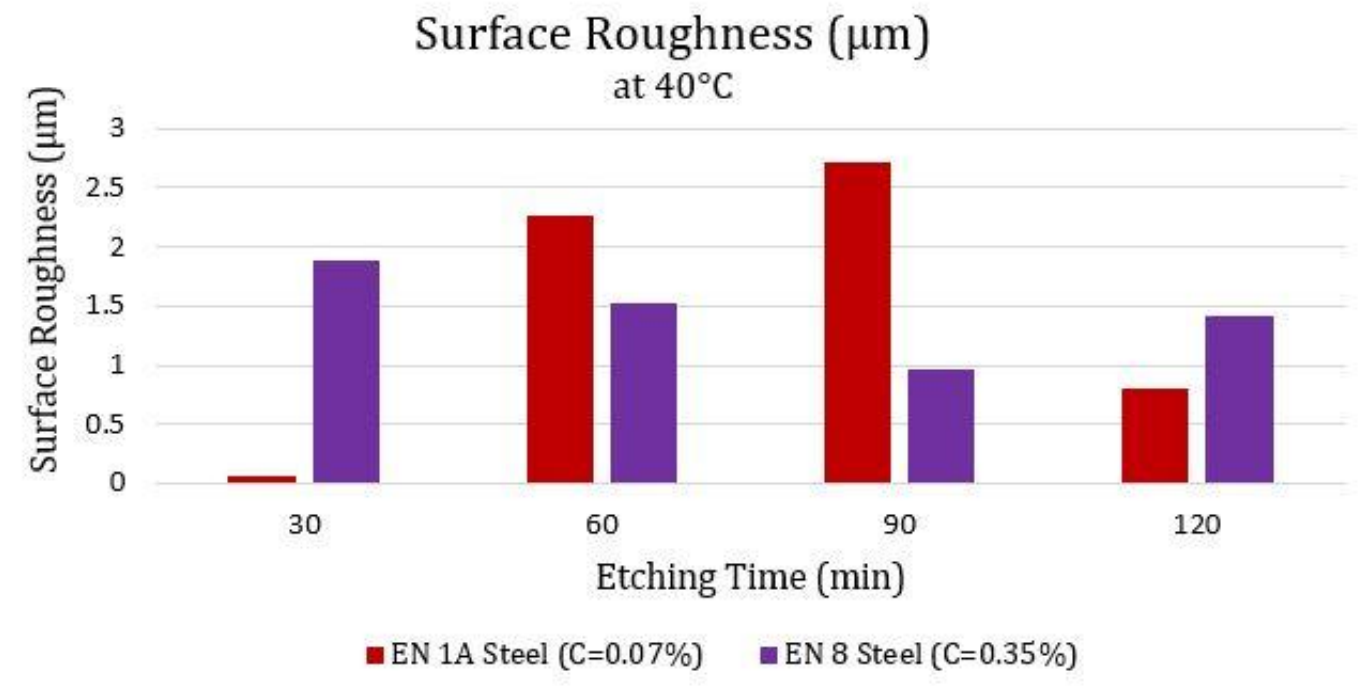

Fig 8. Effect of temp and time on Surface Roughness at $40^{\circ} \mathrm{C}$

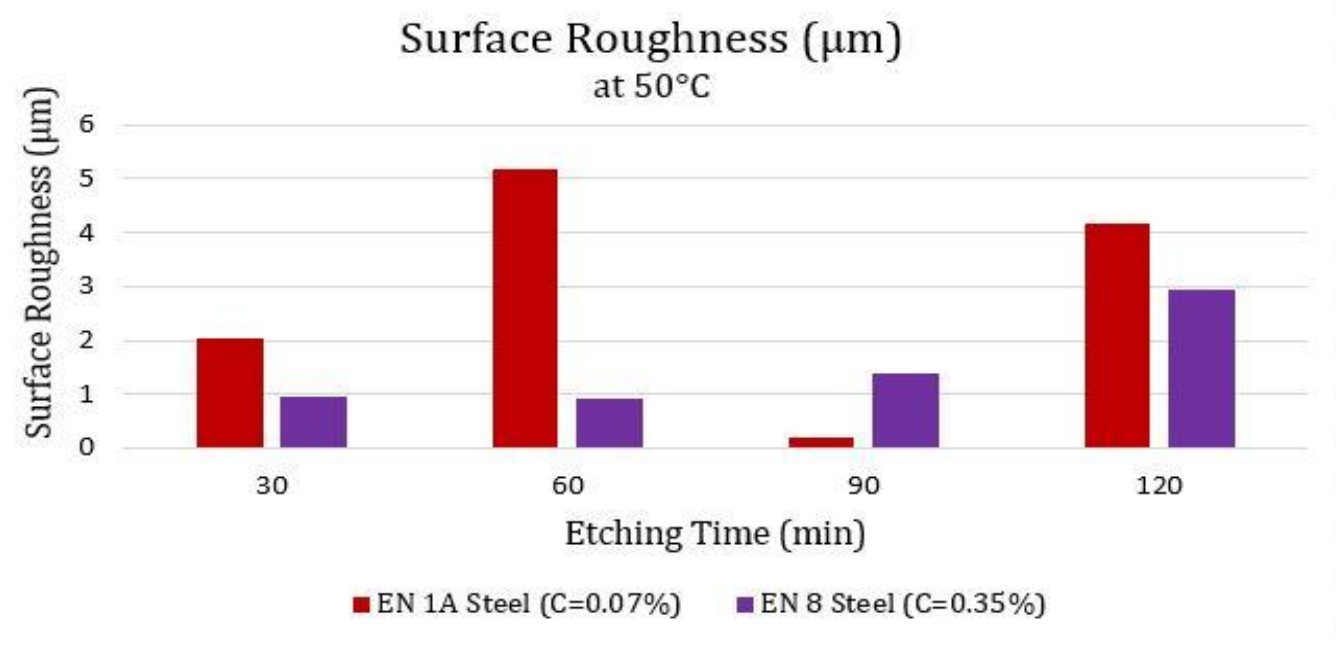

Fig 9. Effect of temp and time on Surface Roughness at $50^{\circ} \mathrm{C}$

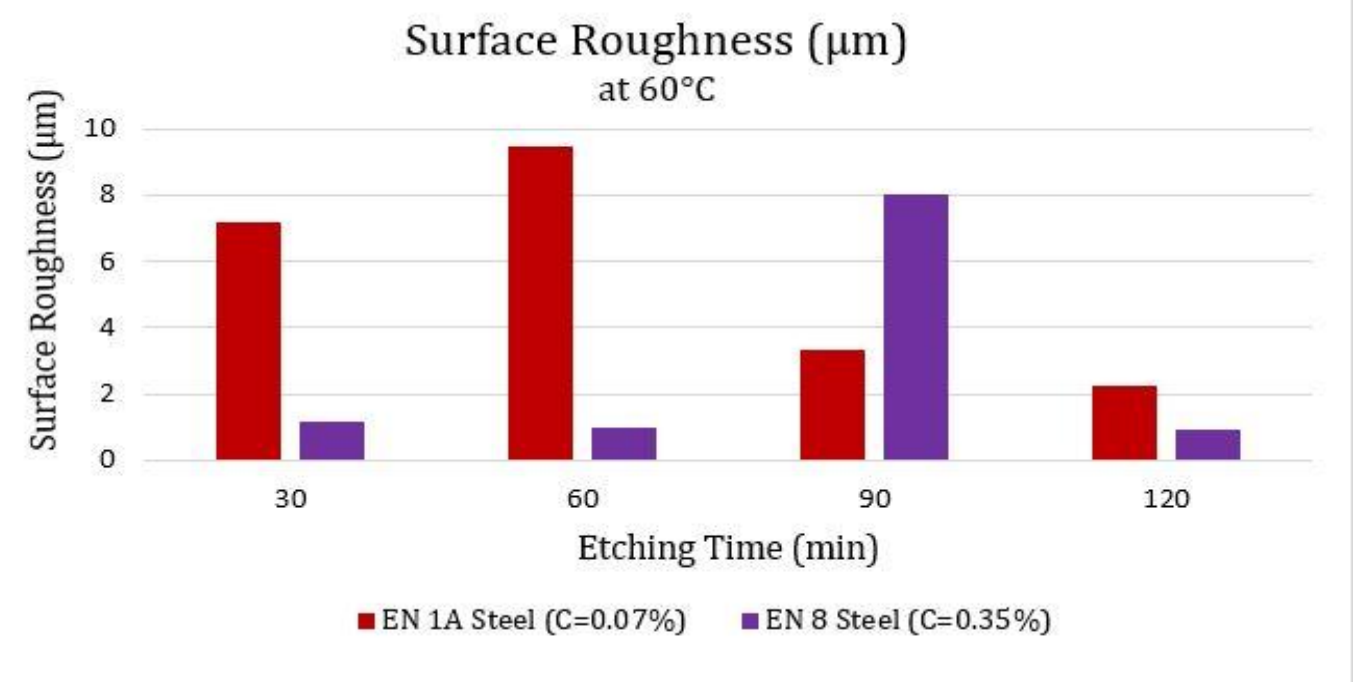

Fig 10. Effect of temp and time on Surface Roughness at $60{ }^{\circ} \mathrm{C}$ 


\section{CONCLUSION}

The current research looks into the depth of etching at different temperatures and times. The etching time and cutting depth were investigated..According to the findings of this study, the following decisions were made. Process parameters were kept constant in this study, and the impact of reaction parameters was investigated by varying etching time and temperature. Etching depth is directly proportional to the energy of light emitted by the photo tool and photoresist thickness. According to OEC values it was observedthat for material $\mathrm{EN} 1 \mathrm{~A}(\mathrm{C}=0.07 \%)$ etching temp $60^{\circ} \mathrm{C}$ and etching time $120 \mathrm{~min}$ is optimal condition and for $\mathrm{EN} 8(\mathrm{C}=0.35 \%)$ Material $50^{\circ} \mathrm{Cand} 120 \mathrm{Min}$ is Optimal condition.

\section{REFERENCES}

[1] Misal N.D. and Sadaiah M. "Investigation on Surface Roughness of Inconel 718 in Photo chemical Machining”, Advances in Materials Science and Engineering, 2017

[2] Misal N.D., Saraf, A.R.andSadaiah M. "Experimental investigation of surface topography in photo chemical machining of Inconel 718", Materials and Manufacturing Processes, vol. 32, no. 15, pp.1756-1763, 2017.

[3] Saraf A.R., Misal N.D. and Sadaiah, M. "Mathematical modelling and optimization ofphoto chemical machining". In Advanced Materials Research, Vol. 548, pp. 617-622, 2012

[4] Barron, A. R. (2009). Composition and Photochemical Mechanisms of PhotoresistsCreative Commons, 1, 1-7.

[5] Diethar Kapp-Schwoerer, Dr. Kurt Meiser, Charles Gantner. (1997). Liquid Resist forPhoto Chemical Machining. (HTP Hi Tech Photopolymer AG, Basel, Switzerland).

[6] Wangikar S.S., Patowari P.P. and Misra, R.D. "Parametric Optimization for Photochemical Machining of Copper Using Grey Relational Method", In Techno-Societal 2016, International Conference on Advanced Technologies for Societal Application, pp. 933-943, 2016.

[7] Kamble, B., Utpat, A.A., Misal, N.D. and Ronge, B.P., 3D Photochemical Machining of Copper By using Colored Photo toolsInternational Journal of New Technology and Research (IJNTR) ISSN: 2454-4116, Volume-5, Issue-7, July 2019 Pages 28-32

[8] Misal, N. D., \&Sadaiah, M. (2018). Multi-objective optimization of Photochemical machining of Inconel 601 using grey relational analysis. Materials Today: Proceedings,5(2), 5591- 5600

[9] Jadhav Saurabh M., Karatkar Onkar V., BangaleKamesh N., Choudhari Deepak B.,Utpat A.A., KambleBanduraj K. (2019) Etching Depth variation of Brass Material for Different Operating ConditionInternational Journal of New Technology and Research (IJNTR) ISSN: 2454-4116, Volume-5, Issue-4, April 2019 Pages 93-96

[10] Sapkal, A. D., A. A. Utpat\&Kamble B (2020). An Experimental Investigation of Etching Depth for Photochemical Machining of Brass.NOVYI MIR Research Journal, Vol 5(9)2020.

[11] Wangikar, S. S., Patowari, P. K., \&Misra, R. D. (2017). Effect of process parameters and optimization for photochemical machining of brass and german silver. Materials and Manufacturing Processes, 32(15), 1747-1755.

[12] Wangikar, S.S., Patowari, P.K., \&Misra, R.D. (2018). Parametric Optimization for Photochemical Machining of Copper using Overall Evaluation Criteria. Materials Today Proceedings. 5(2), 4736-4742, Doi :10.1016/j. matpr.2017.12.046

[13] Wangikar, S. S., Patowari, P. K., Misra, R. D., \&Misal, N. D. (2019). Photochemical Machining: A Less Explored Non-Conventional Machining Process. In Non-Conventional Machining in Modern Manufacturing Systems (pp. 188-201). IGI Global.

[14] Wangikar, S. S., Patowari, P. K., \&Misra, R. D. (2018). Numerical and experimental investigations on the performance of a serpentine microchannel with semicircular obstacles. Microsystem Technologies. 24(8), 3307-3320.

[15] Das, S. S., Tilekar, S. D., Wangikar, S. S., \&Patowari, P. K. (2017). Numerical and experimental study of passive fluids mixing in micro-channels of different configurations. Microsystem Technologies, 23(12), 5977-5988.

[16] Chavan, N. V., Bhagwat, R. M., Gaikwad, S. S., Shete, S. S., Kashid, D. T., \&Wangikar, S. S. (2019). Fabrication \& Characterization of Microfeatures on PMMA Using CO2 Laser Machining. International Journal for Trends in Engineering and Technology. 36(1), 39-32.
[17] Kulkarni, H. D., Rasal, A. B., Bidkar, O. H., Mali, V. H., Atkale, S. A., Wangikar, S. S., \& Shinde, A. B. (2019). Fabrication of Micro-Textures on Conical Shape Hydrodynamic Journal Bearing. International Journal for Trends in Engineering and Technology. 36(1), 37-41.

[18] Raut, M. A., Kale, S. S., Pangavkar, P. V., Shinde, S. J., Wangikar, S. S., Jadhav, S. V., \&Kashid, D. T. (2019) Fabrication of Micro Channel Heat Sink by using Photo Chemical Machining. International Journal of New Technology and Research. 5(4), 72-75.

[19] Patil P. K., Kulkarni A. M., Bansode A. A., Patil M. K., Mulani A. A., Wangikar S. S. (2020) Fabrication of Logos on Copper Material Employing Photochemical Machining. NOVYI MIR Research Journal, 5(6), 70-73.

[20] Wangikar SS, Patowari PK, Misra RD, Gidde RR, Bhosale SB, Parkhe AK (2020) Optimization of photochemical machining process for fabrication of microchannels with obstacles. Materials and Manufacturing Processes, 36:5, 544-557

[21] Bhagwat RM, Gaikwad SS, Shete SS, Chavan NV, Wangikar SS (2020) Study of etchant concentration effect on the edge deviation for photochemical machining of copper. Novyi MIR Res J 5(9):38-44

[22] Kame MM, Sarvagod MV, Namde PA, Makar SC, Jadhav SV, Wangikar SS (2020) Fabrication of microchannels having different obstacles using photo chemical machining process. Novyi MIR Res J 5(6):27-32

[23] Abhay Utpat, N D Misal ,B P Ronge, B A Kamble, "Effect of Process Parameters on Etch Depth of Aluminium Material in Photo Chemical Machining", Advances in Manufacturing Processes, Lecture Notes in Mechanical Engineering. Springer, Singapore, Dec 2020(DOI10.1007/978-981-15-9117-4_7)

[24] S. V. Kulkarni, A. A. Utpat, B.A. Kamble, "Effect of Process Parameters on Etch Depth of Stainless-Steel Material in Photo Chemical Machining by Using Different Etchants", International Journal of New Technology and Research. 7(7), 57-60. 